\title{
TEACHER BURNOUT IN AGRICULTURAL EDUCATION
}

\author{
D. Barry Croom, Assistant Professor \\ North Carolina State University
}

\begin{abstract}
The teaching profession is one of the most visible professions in the world, and even though significant improvements have been made in student achievement, society continues to expect more from its teachers. As the gap widens between the public's expectations of education and the teachers ability to deliver that education, burnout will continue to be a concern. This study sought to determine the level of burnout experienced by agriculture teachers in three southeastern states using the Maslach Burnout Inventory - Educator's Survey. The study found that agricultural teachers experience moderate levels of emotional exhaustion, low levels of depersonalization in relationships with students, colleagues and others, and a high degree of personal accomplishment in their work. An agriculture teacher's gender, academic degree, field preparation method, and annual contract length do not seem to influence teachers' responses on each of the sub-scales of the Maslach Burnout Inventory nor do the size of the school, the type of community, and the size of the agricultural education department. The age and years of teaching experience of the agriculture teacher is related to depersonalization scores, but not to emotional exhaustion and personal accomplishment scores on the Maslach Burnout Inventory.
\end{abstract}

\section{Introduction}

The job of being an agricultural education instructor is both demanding and challenging. Agriculture teachers draw upon physical, emotional and intellectual resources in order to be effective in the classroom (Cano, 1990). Teachers often find themselves working well beyond a 40hour week as they supervise student projects, coach career development teams, evaluate student work and prepare lessons (Straquadine, 1990). The long hours at work, coupled with the stress of teaching could eventually lead to debilitating health problems (Vaughn, 1990). Furthermore, the hazards of laboratory instruction are aggravating stress factors that often lead to chronic health problems and absence from the classroom (Lee, 1990). As a consequence, agriculture teachers are prone to experience a condition called "burnout."

Much of the research in the area of burnout can be traced to Herbert Freudenberger, a psychologist practicing in New York between 1960 and 1979, who used the term to describe the effects of overwork, exhaustion and frustration he experienced while operating a free clinic for drug users and indigent persons. Freudenberger (1974) defined the problem as one of chronic exhaustion and frustration resulting from continued devotion to a goal or principle that has failed to produce a corresponding reward. The term "burnout" originated during the 1960's as a description of the effect of drug abuse on an individual (Golembiewski, 1993).

\section{Theoretical/Conceptual Framework}

Maslach and Jackson (1981) defined burnout as a condition characterized by emotional exhaustion, depersonalization and loss of a sense of personal accomplishment. This condition evolves primarily in individuals who work in human services occupations such as education, social work, police and emergency services. Burnout is manifested in the following ways: work overload, lack of control over one's work environment, lack of community among teachers in the school, lack of fairness in work assignments and the uneven distribution or absence of rewards (Maslach \& Jackson, 1981). Teachers are agents of 
change for many social problems including drug and alcohol abuse, physical, and mental abuse among young people (Maslach, Jackson, \& Leiter, 1996). In addition to these problems, teachers are also expected to provide individualized instruction and enrichment activities even though $24 \%$ of America's classrooms are overcrowded (United States Department of Education, 2000). In the face of these challenging tasks, teachers must teach even though the necessary human and fiscal resources are often lacking (Maslach, Jackson, \& Leiter, 1996). Mullins (1993) reported that the daily job demands placed on teachers were major causes of unrelieved stress. In recent years, the credibility of teachers has been eroded as the public offers competing and often conflicting solutions to the problems of education (Gough, 2000). These conditions have led teachers to leave the profession prematurely (Maslach et al., 1996).

Harden (1999) found that teachers must often organize instruction based upon some standardized curriculum which limits control over what is taught in the classroom. Teachers report that not having discretion on how to complete their work and the demand to conform to system-wide norms are stressors that may lead to burnout. The Demand-Control Model proposed by Karasek and Theorell (1990) identified the ability to make decisions in a demanding work environment as most likely to cause job strain. Hall and Savery (1987) found that stress at work was a result of this lack of decision-making authority. Teachers who had a wide degree of decision latitude tend to view problems as challenges and work to overcome them in positive ways. Therefore, it can be predicted that teaching in an environment with heavy workloads and low decision latitude leads to burnout (Stoner \& Wankel, 1986). It is not necessarily the intensity of stressful events that causes burnout. It is, in part, the result of the constant hammering of stress on the individual's psyche (Hobfall \& Shirom, 1993).

Teachers do not have a significant influence over the daily school schedule nor do they have a real voice in the decisionmaking apparatus within a school administration (Maslach \& Leiter, 1997). In a study of the teachers at one urban high school, Byrne (1998) found that 98\% of teachers surveyed reported that the educational bureaucracy was the chief cause of burnout. Byrne (1998) further suggested that the overwhelming perception of an ineffective bureaucracy stems from the inability of some urban school systems to provide the necessary resources teachers need in order to teach. Teachers in Byrne's study (1998) reported that one major cause of low morale was the ineffectiveness of the administration efforts to alleviate the workload. The Metropolitan Life Corporation (2002) supported this assertion and finds that nearly $30 \%$ of teachers believe that their opinions do not matter to school administrators. Teachers desire to have an impact in the classroom, and the risk of burnout escalates when too many non-instructional duties and an overload of responsibilities are the norm (Metropolitan Life Corporation, 2002).

Maslach et al. (1996) reported that for many teachers, the sustaining force behind their decision to remain in teaching is the personal accomplishment they feel in teaching students. Consequently, teachers are highly susceptible to burnout when their perception of personal accomplishment is diminished by organizational and social factors. Maslach et al. (1996) notes that the teaching career is relatively flat with little opportunity for hierarchical advancement, and regardless of how many hours teachers work, there is very little opportunity for additional pay. Teachers have not gained much ground in salaried compensation since 1991. The United States Department of Education (2002) reported that teachers' salaries, when measured in constant dollars, have only increased 5\% nationally in the last 10 years. The teaching profession is one of the most visible professions in the world. Even though significant improvements have been made in student achievement, society continues to expect more and more from its teachers. As the gap widens between the public's expectations of education and the teachers ability to deliver that education, burnout will continue to be prevalent (National School Boards Association, 2002). 


\section{Purpose}

The purpose of this study was to determine: 1) the extent to which agricultural education instructors experience personal accomplishment in their work; 2) the extent to which agricultural education instructors experience depersonalization in relationships with students, colleagues and others; 3) the extent to which agricultural education instructors experience emotional exhaustion in their work; 4) if burnout among agriculture teachers is influenced by selected teacher characteristics, and 5) if burnout among agriculture teachers is influenced by selected school and community characteristics.

\section{Procedures}

The population for this descriptive study was agriculture teachers in three states in the southeastern United States. Using Cochran's formula, a proportional sample of 248 teachers was selected from approximately 700 agricultural education instructors in the three states (Cochran, 1977). The Maslach Burnout Inventory - Educator's Survey (MBI-ES) was the instrument used to determine the frequency of burnout in respondents. The MBI-ES is the predominant instrument used to assess burnout in teachers and educational administrators (Maslach, Jackson, \&
Schwab, 1986). The MBI-ES consists of 22 statements describing the feelings an individual might have as a result of being over-stressed or burne-dout. Respondents were asked to indicate the frequency at which they experienced these feelings by selecting from six response choices that ranged from 0 (Never) to 6 (Everyday). The MBI-ES measures burnout on three subscales: Emotional Exhaustion - Chronic emotional fatigue resulting from counseling and teaching a large number of individuals on a continual basis; Depersonalization - An indifferent and negative attitude toward students characterized by the use of disparaging labels to describe students, and Personal Accomplishment - The contribution a teacher makes for the wellbeing and intellectual advancement of students.

Feelings of low personal achievement can lead to burnout. The response scale for personal accomplishment is different from the other two sub-scales because the scoring is reversed. That is, a score of less that 32 on the personal accomplishment sub-scale means a high degree of personal accomplishment. The response categories and their corresponding values for emotional exhaustion, depersonalization and personal accomplishment on the Maslach Burnout Inventory - Educators' Survey (Maslach et al., 1996) are presented in Table 1. 
Table 1

Response Categories for Emotional Exhaustion, Depersonalization and Personal Accomplishment on the Maslach Burnout Inventory - Educators' Survey

\begin{tabular}{lccc}
\hline Response Category & Emotional Exhaustion & Depersonalization & $\begin{array}{c}\text { Personal } \\
\text { Accomplishment }\end{array}$ \\
\hline High & 27 or over & 13 or over & $0-31$ \\
Moderate & $17-26$ & $7-12$ & $32-38$ \\
Low & $0-16$ & $0-6$ & 39 or over
\end{tabular}

Note. The numerical values for the personal accomplishment subscale are reversed. A score of less that 32 on the personal accomplishment sub-scale indicates a high degree of personal accomplishment.

The MBI-ES is not designed to label individuals as burned-out. Instead, it is most beneficial in identifying areas within the school system that would improve the working conditions for teachers. Studies by Iwanicki and Schwab (1981) and Gold (1984) validated the three-factor structure of the instrument. Iwanicki and Schwab's (1981) measure of internal consistency yielded a Cronbach's alpha coefficient of .90 for Emotional Exhaustion, .76 for Depersonalization, and .76 for Personal Accomplishment. Gold's (1984) Cronbach's alpha coefficient yielded .90 for Emotional Exhaustion, .74 for Depersonalization, and .72 for Personal Accomplishment. This study yielded a Cronbach's coefficient alpha of .90 for Emotional Exhaustion, .75 for Depersonalization, and .77 for Personal Accomplishment.

The agriculture teachers were mailed an introductory letter and survey instrument. Subsequent mailings to non-respondents were made and the final response rate was $66 \%$ or 164 respondents. Early respondents $(n=127)$ were compared to late respondents $(n=37)$ and no significant differences were found to exist (Miller \& Smith, 1983). Descriptive statistics were generated on the demographic data and each item on the survey instrument. A univariate analysis of variance was performed to determine if differences exist between the scores of participants in the study with regard to selected demographic characteristics. The individual teacher characteristics of gender, educational level, teacher preparation, and contract length; and the school characteristics of school size, community type, block scheduling, and agricultural education department size were the independent variables. The three burnout sub-scales of Emotional Exhaustion, Depersonalization and Personal Accomplishment were the dependent variables. The Pearson Product Moment correlation statistic was used to determine if a relationship existed between the years of teaching experience and emotional exhaustion, depersonalization and personal accomplishment. The Pearson Product Moment correlation statistic was also used to determine if a relationship existed between the age of instructors and emotional exhaustion, depersonalization, and personal accomplishment.

\section{Findings}

Males made up $76 \%$ of the sample. Teachers with a degree in agricultural education comprised the majority of respondents $(86.7 \%)$ and $46 \%$ had either earned an advanced degree beyond the baccalaureate level or had completed some type of post-baccalaureate work. One-third of teachers in the sample $(n=109)$ held 12- 
month contracts. The largest group of respondents taught in either a single-teacher program $(42.4 \%)$ or a two-teacher program $(38.2 \%)$. Rural communities made up slightly more than half of the communities in which agricultural education programs in this study reside. Schools with less than
1,000 students were $57.9 \%$ of the sample. Teachers from multiple-teacher programs made up $56 \%$ of the respondents. Table 2 presents respondent characteristics and the corresponding mean scores for each subscale of the Maslach Burnout Inventory.

Table 2

Demographic Characteristics and the Corresponding Mean Scores for Each Sub-Scale of the Maslach Burnout Inventory

\begin{tabular}{lccrc}
\hline Characteristic & $\begin{array}{c}\text { Emotional } \\
\text { Exhaustion } \\
N=164\end{array}$ & $\begin{array}{c}\text { Depersonalization } \\
N=164\end{array}$ & $\begin{array}{c}\text { Personal } \\
\text { Accomplishment } \\
N=164\end{array}$ \\
\hline$M \quad S D$ & $M$ & $S D$ & $M \quad$ & $S D$
\end{tabular}

Gender

$\begin{array}{lrrrrrr}\text { Male } & 17.66 & 9.88 & 5.81 & 4.67 & 8.25 & 5.83 \\ \text { Female } & 20.94 & 11.00 & 7.15 & 6.54 & 7.38 & 6.53\end{array}$

Teacher Preparation

$\begin{array}{lrrrrrr}\text { Pre-service } & 16.63 & 8.88 & 4.86 & 2.96 & 7.36 & 5.84 \\ \text { Lateral Entry } & 18.84 & 10.47 & 6.36 & 5.44 & 8.15 & 6.01\end{array}$

Degree Held

$\begin{array}{lrrrrrr}\text { Baccalaureate } & 19.29 & 10.22 & 6.54 & 5.18 & 7.94 & 5.90 \\ \text { Above Baccalaureate } & 17.71 & 10.32 & 5.69 & 5.19 & 8.17 & 6.10\end{array}$

Annual Contract Length

$\begin{array}{lrrrrrr}\text { 12-Month } & 18.19 & 10.25 & 6.06 & 5.19 & 8.17 & 6.24 \\ 11-\text { Month } & 19.51 & 11.40 & 5.90 & 5.06 & 7.32 & 5.58 \\ \text { 10-Month } & 20.88 & 9.95 & 6.94 & 5.92 & 7.94 & 6.00\end{array}$


$\underline{\text { Table } 1 \text { Continued }}$

\begin{tabular}{lcccc}
\hline Characteristics & $\begin{array}{c}\text { Emotional } \\
\text { Exhaustion } \\
N=164\end{array}$ & $\begin{array}{c}\text { Depersonalization } \\
N=164\end{array}$ & $\begin{array}{c}\text { Personal } \\
\text { Accomplishment } \\
N=164\end{array}$ \\
\hline$M$ & $S D$ & $M$ & $S D$ & $M \quad S D$
\end{tabular}

Community Type

$\begin{array}{lrrrrrr}\text { Urban } & 18.98 & 11.97 & 5.78 & 5.27 & 8.65 & 6.55 \\ \text { Suburban } & 18.18 & 8.21 & 7.04 & 4.94 & 8.09 & 5.47 \\ \text { Rural } & 18.58 & 9.73 & 6.35 & 5.22 & 7.86 & 5.74\end{array}$

School Population Size

$\begin{array}{lrrrrrr}\text { Under 1,000 students } & 18.30 & 10.35 & 6.05 & 5.35 & 7.68 & 5.72 \\ \text { Over 1,000 students } & 18.07 & 10.72 & 5.85 & 5.03 & 8.55 & 6.33\end{array}$

Department size

$\begin{array}{lllllll}\text { Two or more teachers } & 18.93 & 10.45 & 6.57 & 5.77 & 8.06 & 5.77\end{array}$

$\begin{array}{lllllll}\text { One teacher } & 18.05 & 10.09 & 5.60 & 4.29 & 8.02 & 6.28\end{array}$

Note. Emotional Exhaustion: 0-16 = Low, 17-26 = Moderate, $>27=$ High; Depersonalization: 0-6 =Low, 7-12 = Moderate, $>13=$ High; Personal Accomplishment: $>39=$ Low, 32-38 = Moderate, 0-31 = High.

A Comparison of Respondents'

Scores to National Norms

Compared to national norms for secondary teachers (Maslach et al., 1996), agriculture teachers are below the national average for emotional exhaustion and depersonalization and above the national average for personal accomplishment. The comparison of respondent's scores to national norms is presented in Table 3. 
Table 3

The Comparison of Respondents Scores to National Norms

\begin{tabular}{lcccc}
\hline Burnout Scales & \multicolumn{2}{c}{$\begin{array}{c}\text { Agriculture Teachers } \\
n=164\end{array}$} & \multicolumn{2}{c}{$\begin{array}{c}\text { National Norms For } \\
\text { Secondary Teachers } \\
n=4,163\end{array}$} \\
& $M$ & $S D$ & $M$ & 11.01 \\
Emotional Exhaustion & 18.20 & 10.47 & 21.25 & 6.19 \\
Depersonalization & 5.96 & 5.21 & 11.00 & 6.89 \\
Personal Accomplishment & 8.04 & 5.98 & 33.54 &
\end{tabular}

Note. Emotional Exhaustion: 0-16 = Low, 17-26 = Moderate, $>27=$ High; Depersonalization: 0 $6=$ Low, $7-12=$ Moderate, $>13=$ high; Personal Accomplishment: $>39=$ Low, 32-38 = Moderate, $0-31=$ High.

The Extent to Which Agricultural Education Instructors Experience Emotional Exhaustion

Using Maslach's scale as described in Table $1,48 \%$ of the respondents reported a low degree of emotional exhaustion from their work. The mean score for respondents was $18.20(S D=10.47)$ indicating moderate emotional exhaustion. Almost 33\% of participants experienced moderate degrees of emotional exhaustion and $19 \%$ reported a high degree of emotional exhaustion. However, at least a few times per month, a few teachers in this study feel completely exhausted at the end of the school day $(M=3.20, S D=1.62)$ and emotionally drained by the experience $(M=2.91, S D=1.62)$. A few teachers also report that they believe they are occasionally putting too much effort into their work $(M=2.76, S D=1.73)$. To an even lesser extent, teachers are finding themselves frustrated $(M=2.35, S D=1.57)$ and burned out $(M=1.88, S D=1.53)$ from the teaching experience. Finally, teachers rarely find themselves adversely reacting in situations where they must work with others $(M=1.17, S D=1.27)$. Teaching and working with others is not overly stressful $(M=.87$, $S D=1.06)$ to agricultural education teachers. Table 4 presents respondents' scores for emotional exhaustion. 
Table 4

Mean Scores of Respondents on Emotional Exhaustion in Teaching

\begin{tabular}{lll}
\hline Item Description & $M$ & $S D$
\end{tabular}

I feel used up at the end of the workday.

$3.20 \quad 1.62$

I feel emotionally drained from my work.

$2.91 \quad 1.62$

I feel I'm working too hard on my job.

2.76

1.73

I feel frustrated by my job.

I feel fatigued when I get up in the morning and have to face another day

$2.15 \quad 1.67$ on the job.

I feel burned out from my work.

Working with people all day is really a strain for me.

I feel like I'm at the end of my rope.

Working directly with people puts too much stress on me. $.87 \quad 1.06$ Note. $0=$ Never; $1=\mathrm{A}$ Few Times a Year or Less; $2=$ Once a Month or Less; $3=\mathrm{A}$ Few Times a Month; 4 = Once a Week; 5 = A Few Times a Week; and 6 = Everyday.

The Extent to Which Agricultural Education Instructors Experience Depersonalization

The overall mean score for respondents was $5.96(S D=5.21)$ indicating a low degree of depersonalization. Sixty-four percent of respondents reported that they were experiencing a low degree of depersonalization in their relationship with others $(M=1.45, \quad S D=1.45)$ while $24 \%$ reported moderate degrees of depersonalization and $12 \%$ reported high degrees of depersonalization. They perceived that students were blaming them for their problems only a few times during the academic year. Teachers rarely exhibited a callous attitude toward others $(M=1.49$, $S D=1.69)$ and their concern that their teaching role was hardening their emotions was similarly infrequent $(M=1.24$, $S D=1.54)$. An uncaring attitude toward students $(M=.96, S D=1.37)$ and a disposition to treat students as impersonal objects $(M=.95, S D=1.21)$ occurred in very rare instances. Table 5 shows the respondents' scores on depersonalization. 
Table 5

Mean Scores of Respondents on Depersonalization at Work

Item Description

\section{$M$}

$S D$

I feel students blame me for their problems.

I've become more callous toward people since I took this job.

I worry that this job is hardening me emotionally.

.96

.95

1.45

I don't really care what happens to some students.

I feel I treat some students as if they were impersonal objects.

1.45

Note. $0=$ Never; $1=$ A Few Times a Year or Less; $2=$ Once a Month or Less; $3=$ A Few Times a Month; 4 = Once a Week; To $5=$ A Few Times a Week; and $6=$ Everyday.

The Extent to Which Agricultural

Education Instructors Experience Personal Accomplishment

The mean score for respondents was $8.04(S D=5.98)$ indicating a high degree of personal accomplishment. None of the individual respondents scores fell outside of the high personal accomplishment range on the scale. All of the scores were in the range identified by Maslach et al. (1996) as indicative of high personal accomplishment. Teachers feel exhilarated by working with students and energetic about their work.
They deal with emotional problems in a calm manner and are adept at expressing empathy toward students. They see themselves as being influential in helping students solve problems. Respondents believe they have accomplished many worthwhile things and are a positive influence in the lives of students. They also create a relaxed learning environment in which students can learn. Table 6 describes respondents' scores on personal accomplishment at work. 
Table 6

Mean Scores of Respondents on Personal Accomplishment at Work

\begin{tabular}{llc}
\hline Item Description & $M$ & $S D$ \\
\hline I feel exhilarated after working closely with my students. & 1.54 & 1.49 \\
I feel very energetic. & 1.46 & 1.41 \\
In my work, I deal with emotional problems very calmly. & 1.45 & 1.54 \\
I can easily understand how my students feel about things. & 1.32 & 1.52 \\
I have accomplished many worthwhile things in this job. & 1.26 & 1.31 \\
I deal very effectively with the problems of my students. & .90 & 1.32 \\
I feel I'm positively influencing other people's lives through my work. & .87 & 1.17 \\
I can easily create a relaxed atmosphere with my students. & .78 & 1.18
\end{tabular}

Note. $6=$ Never; 5 = A Few Times a Year or Less; $4=$ Once a Month or Less; $3=$ A Few a Month; 2 = Once a Week; 1 = A Few Times a Week; and $0=$ Everyday.

\section{The Influence of Selected Teachers, School and Community Characteristics on \\ Emotional Exhaustion, Depersonalization and Personal Accomplishment}

The results of the analysis show that individual teacher characteristics of gender $(F=.105)$, educational level $(F=.778)$, teacher preparation $(F=2.27)$, and contract length $(F=.067)$, had no significant effect on the emotional exhaustion, depersonalization and personal accomplishment of respondents. The results of the analysis show that school size $(F=.079)$, community type $(F=.209)$, and agricultural education department size $(F=.000)$ also had no a significant effect on emotional exhaustion, depersonalization and personal accomplishment. Furthermore, there were no significant differences identified in the interaction effects between the demographic variables and the three burnout sub-scales.

The Relationship Between Age and Years of Teaching Experience and Emotional Exhaustion, Depersonalization and Personal Accomplishment.
In order to test the significance of the relationship between the respondents' age and years of teaching experience and emotional exhaustion, depersonalization, and personal accomplishment, Pearson Product Moment Correlation Coefficients were computed. A significant negative relationship was found between teacher age and depersonalization $(r=-.20)$. Using the Davis convention for determining the strength of relationships (Davis, 1981), a low negative association was found to exist between teacher age and depersonalization. No significant relationship was found between teacher age and emotional exhaustion, and personal accomplishment. No significant relationships were found to exist between years of teaching experience and emotional exhaustion, and teaching experience and personal accomplishment. A low negative association was also found to exist between the years of experience teaching and depersonalization $(r=-.26)$. 


\section{Conclusions}

Based upon the findings of this study, burnout is not a serious problem for agriculture teachers. While there are indications that teachers are experiencing some level of stress, these stress levels have not reached the point where burnout is a problem. An analysis of the data has yielded the following conclusions about teacher burnout in agricultural education:

1. Agriculture teachers experience moderate levels of emotional exhaustion in their work, low levels of depersonalization in relationships with students, colleagues, and others, and a high degree of personal accomplishment in their work.

2. Gender, academic degree, field preparation method, annual contract length, school size, the type of community, and the number of teachers in the agricultural education department do not seem to influence teachers' responses on each of the sub-scales of the Maslach Burnout Inventory.

3. The age and years of teaching experience of the agriculture teacher is related to depersonalization scores on the Maslach Burnout Inventory. As teachers get older and more experienced, they may develop coping skills to alleviate the tendency to treat students in an impersonal manner. The age of the agriculture teacher and the years of teaching experience are not related to emotional exhaustion and personal accomplishment scores on the Maslach Burnout Inventory.

\section{Discussion}

In spite of personal and environmental conditions that place teachers at risk of burnout, agriculture teachers appear to be managing well. Agriculture teachers see themselves as energetic and engaged professionals who are accomplishing something worthwhile for the benefit of students. They work to create an environment where learning flourishes.
Building rapport with students is important to teachers, and they consider it part of their to duty to help students develop coping mechanisms to deal with everyday problems. The best interests of the students are important. As teachers get older and more experienced in teaching, they tend to develop coping skills that alleviate work stress. This research study found that teachers tended to find ways to combat fatigue and to prevent treating students as impersonal objects. Teachers occasionally worry that students blame them for problems they are experiencing, and sometimes perceive that the job has caused them to become uncompassionate. Even though the results of this study suggest that our teachers are not burned-out, the results of the study indicated a moderate level of emotional exhaustion. Generally, the more emotionally fatigued agriculture teachers become, the more likely their teaching performance is going to suffer (Brouwers \& Tomic, 2000). However, the respondents in this study had very high scores on personal accomplishment, and as long as they are able to maintain that high degree of selfefficacy, the effects of emotional exhaustion should probably not be a cause for concern.

\section{Implications And Recommendations}

\section{Teacher Recruitment}

Some potential teachers (e.g., former state FFA officers, people with agricultural degrees working in industry) have considered becoming certified to teach but have decided against teaching because they do not want to take on a career that will lead to burnout and dissatisfaction. The reality is that teachers have a high degree of satisfaction with their accomplishments and burnout is not a major problem for those teachers who stay in the profession and develop coping mechanisms. This needs to be communicated clearly to potential teachers. The perception that agricultural education instructors are at high risk of burnout is not an accurate picture.

\section{Teacher Training}

In our teacher education classes, we need to instruct our students about the 
potential for burnout in the profession. We should also provide them with suggestions and strategies for coping with stress. A discussion among student teachers about job burnout may seem out of place considering their newness to the profession, but that is precisely the time in which they should learn measures to prevent it from happening. Student teachers will expect these situations and be better prepared to handle them. When planning in-service education activities for teachers, educators might wish to consider planning activities based on some of the trends identified in this research.

\section{Beyond Agricultural Education}

The agricultural education profession has a responsibility beyond the preparation of teachers for the classroom. The profession must be involved in the social and political forces that drive education and should exert an influence to improve the environment and organizational structure in which agriculture teachers teach. The profession should seek ways to encourage a sense of community within the school setting and work with fellow educators in other disciplines to encourage communication and supportive attitudes among teachers and administrators alike. Teacher educators are not only training the teachers of tomorrow, but future school administrators as well. There is potential to steer the course of education toward a system where the teacher has more autonomy and decision-making responsibilities.

For further research, it is recommended that the profession investigate the effect of school reform on teacher burnout. Have school reform efforts such as site-based management, peer coaching, and increased parental involvement alleviated teacher burnout? A longitudinal study of the effects of school reform on teacher burnout in agricultural education would be useful. It is further recommended that researchers investigate the effects of induction programs for new agriculture teachers. Have induction programs successfully taught new teachers how to deal with the stress and demands of teaching agriculture, particularly for those teachers in year-round programs? It would be valuable to study the ways that teachers are socialized into the teaching profession and inoculated against common stresscausing agents. Researchers should also consider additional research into coping skills for burnout and stress. Finally, researchers should investigate burnout among teachers who have exited the profession. This study only examined those teachers still in the classroom. It would be beneficial to study those teachers who have left the profession to ascertain whether or not burnout was a contributing factor to their decision to leave.

\section{References}

Brouwers, A., \& Tomic, W. (2000). A longitudinal study of teacher burnout and perceived self-efficacy in classroom management. Teaching and Teacher Education, 16, 239-253.

Byrne, J.J. (1998). Teacher as hunger artist: Burnout: Its causes, effects and remedies. Contemporary Education 69(2), 86-91.

Cano, J. (1990, June). Teacher stress Teacher burnout: A profession at risk. The Agricultural Education Magazine, 62(12), 13-14, 22.

Cochran, W.G. (1977). Sampling techniques. New York, NY: Wiley.

Davis, J.A. (1971) Elementary survey analysis. Englewood, NJ: Prentice Hall.

Freudenberger, H. (1974). Burnout: The high cost of high achievement. Garden City, NY: Anchor Press.

Gold, Y. (1984). The factorial validity of the Maslach Burnout Inventory in a sample of California elementary and junior high school classroom teachers. Educational and Psychological Measurement, 44, 10091016.

Golembiewski, R.T. (Ed.). (1993). Handbook of organizational behavior. New York, NY: Marcel Dekker. 
Gough, P.B. (2000, November). Bring on the pachyderms. Phi Delta Kappan, 82(3), 183.

Hall, K., \& Savery, L.K. (1987), Stress management. Management Decision, 25(6), 29-35.

Harden, R.M. (1999) Stress, pressure and burnout in teachers: Is the swan exhausted? Medical Teacher 21(3), 245247.

Hobfall, S.E., \& Shirom, A. (1993). Stress and burnout in the workplace. In R.T. Golembiewski (Ed.), Handbook of organizational behavior (pp. 41-60). New York, NY: Marcel Dekker.

Iwanicki, E.F. \& Schwab, R.L. (1981). A cross-validational study of the Maslach burnout inventory. Educational and Psychological Measurement, 41, 1167-1174.

Karasek, R.A. \& Theorell, T. (1990). Healthy work. New York, NY: Basic Books.

Lee, J.S. (1990, November). How healthy are agriculture teachers? The Agricultural Education Magazine, 62(12), 6, 21.

Maslach, C., \& Jackson, S.E. (1981). MBI: Maslach burnout inventory. Palo Alto, CA: Consulting Psychologists Press.

Maslach, C., Jackson, S.E., \& Leiter, M.P. (1996). Maslach burnout inventory manual ( $3^{\text {rd }}$ ed.). Palo Alto, CA.: Consulting Psychologists Press.

Maslach, C., \& Leiter, M.P. (1997). The truth about burnout. San Francisco, CA: Jossey-Bass.

Maslach C., Jackson, S.E. \& Schwab, R.L. (1986). Maslach burnout inventory: Educators survey. Palo Alto, CA.: Consulting Psychologists Press.
Metropolitan Life Corporation. (2002). Survey of the American teacher. Retrieved May 27, 2002, from http://www.metlife .com/Applications/Corporate/WPS/CDA/Pa geGenerator/0,1674,P2315,00.html.

Miller, L. E., \& Smith, K. L. (1983). Handling nonresponse issues. Journal of Extension, 21 (September/October), 45-50.

Mullins, L.J. (1993). Management and organizational behavior. ( $3^{\text {rd }}$ ed.). London: Pitman Publishing.

National School Boards Association. (2002). Change and education. Retrieved May 27 2002, from: www.nsba.org/sbot/ toolkitchned.html.

Stoner, J.A.F., \& Wankel, C. (1986). Management. ( $3^{\text {rd }}$ ed.). Englewood Cliffs, NJ: Prentice-Hall.

Straquadine, G.S. (1990, December). Work, is it your drug of choice? The Agricultural Education Magazine, 62(12), 11-12, 21.

United States Department of Education, National Center for Educational Statistics. (2000). The condition of education 2001. Washington, DC: Author.

United States Department of Education, National Center for Educational Statistics. (2002). Estimated average annual salaries of classroom teachers in public elementary and secondary schools with alternative projections: 1985-86 to 2010-11. Retrieved May 27, 2002 from: http://nces.ed.gov/ pubs2001/proj01/tables/table35.asp.

Vaughn, P.R. (1990, December). Agricultural education: Is it hazardous to your health? The Agricultural Education Magazine, 62(12), 4. 